\title{
Design and Efficiency Evaluation of Nano-Positioning System in Macro Scale with Circular Flexture Joints
}

\author{
Maziar Sadeghi ${ }^{1}$, Alireza Zarreh², Mahmoud Mosavi Mashadi ${ }^{3}$ \\ Department of Manufacturing, School of Mechanical Engineering, College of Engineering, University of Tehran, Tehran, \\ Iran \\ maziar.sadeghi@gmail.com
}

\begin{abstract}
:
Nanopositioning devices are precise mechatronic systems, which have high resolution, normally in the range of 1 to 100 nanometers. This paper is designing, modeling, and fabrication evaluation of a macro compliant mechanism for nanopositioning employing flexure joints. This device is applicable in various processes that need tool movement with the precision of the nano range. Firstly, the basic principles of designing a positioning mechanism, according to flexibility and stiffness are surveyed. Then, the paper simplifies the equations, only lumped approximation of flexure joints in the pseudo-rigid-body approach was considered and the differential kinematics was used. Finally, the mechanism is modeled by finite element software and the results of modeling proved capabilities and technical specifications of the designed mechanism according to the analysis and illustrate its applicability for nanopositioning.
\end{abstract}

\footnotetext{
${ }^{1}$ M.Sc. of Mechanical Engineering, Manufacturing

${ }^{2}$ M.Sc. of Mechanical Engineering, Manufacturing

${ }^{3}$ Professor of Mechanical Engineering
} 


\title{
طراحى و بررسى كارايى يك دستكاه موقعيت دهى ابزار نانو در ابعاد ماكرو با مفصل خمشى دايره اى
}

\author{
مازياز صادقى'، على رضا ذرّه'، محمود موسوى مشهدى" \\ دانشكًا تيران، يرديس دانشكده هاى فنى، انشكده مكانيك، كروه ساخت و توليد
}

maziar.sadeghi@gmail.com

\section{جكيده}

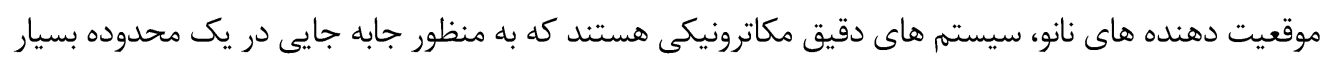

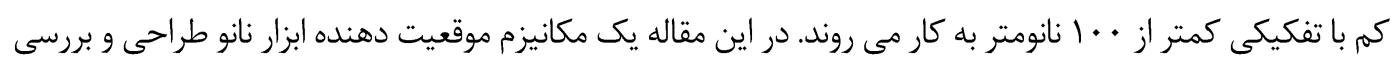

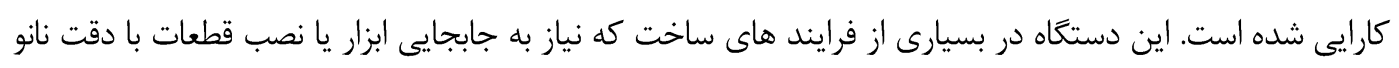

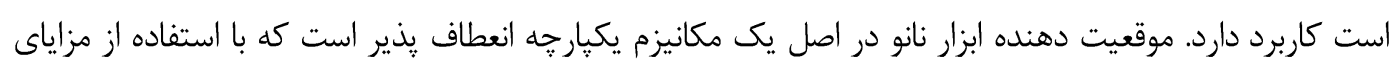

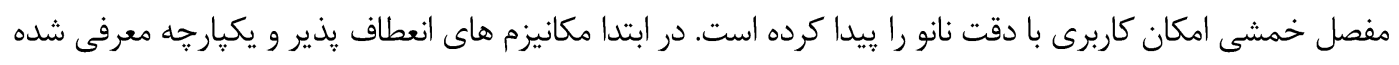

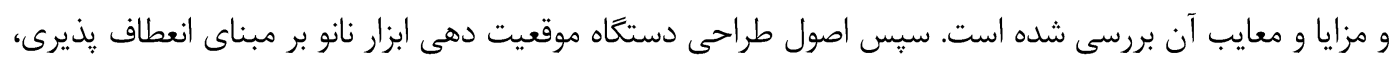

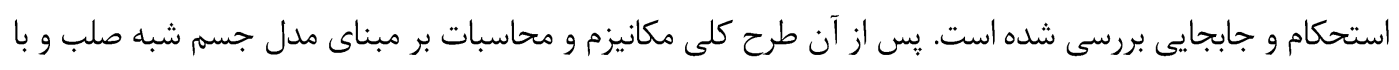

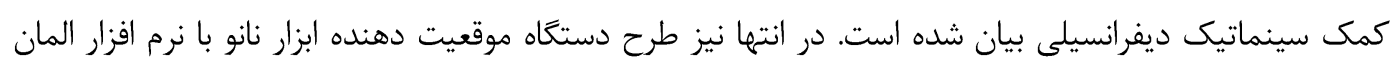

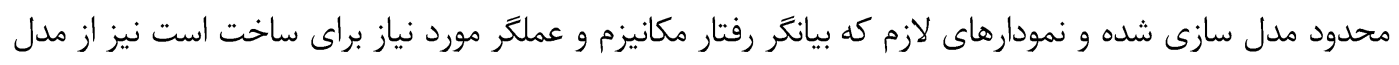

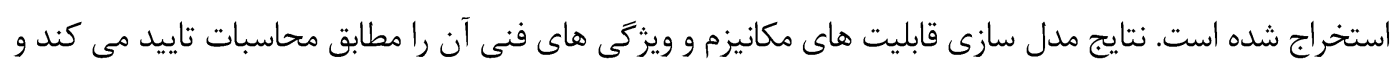

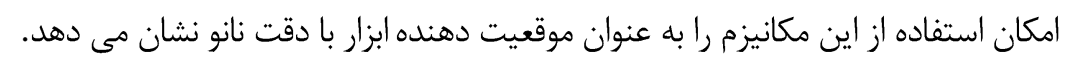

$$
\begin{aligned}
& \text { ' كارشناسى ارشد مهندسى مكانيك ساخت و توليد }
\end{aligned}
$$

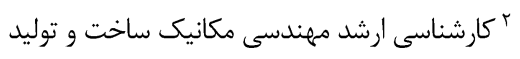

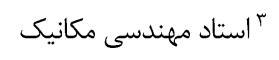


يك مكانيزم وسيله اى مكانيكى است كه براى انتقال يا تبديل جابجايى، نيرو و انرزى به كار مى رود [اوץr]. مكانيزم هاىمرسوم از

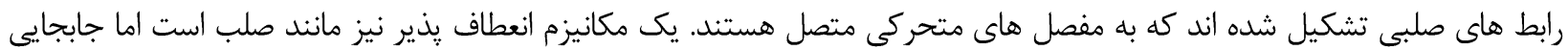
اش را بيشتر از خمش رابط هاى انعطاف يذير خود مى گيرد. مفاصل خمشى صدها سال در ابزارهاى دقيق كاربرد داشته اند و نسبت به به هابه

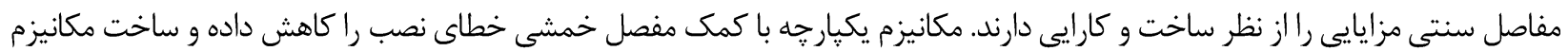

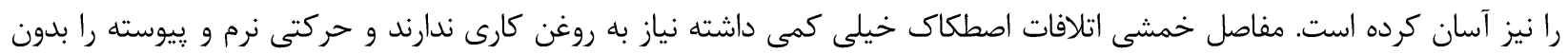
برگشت فنرى فراهم مى كنند.

اصول طراحى سازه انعطاف يذير با سازه هاى صلب متفاوت است. از اين جهت طراح بايد آكاهى دقيقى نسبت به مفاهيم سفتى، انعطاف يذيرى و استحكام داشته و تاثير ابعاد و جنس ماده را روى اين مفاهيم بداند. بدين ترتيب با طراحى صحيح هندسه و انتخاب درست ماده اوليه مفاصل خمشى در مكانيزم انعطاف يذير ارتباطى تكرار يذير و قابل ييش بينى بين نيرو و جابجايى فراهم مى شود. ويزگى ها و

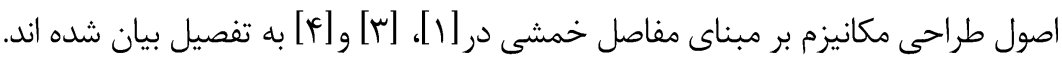
در [له- [Vمونه هايى از طراحى و بهينه سازى ابعادى مكانيزم انعطاف يذير آمده و در [مو 9] نيز با استفاده از نرم افزار هاى المان محدود مكانيزم ها طراحى شده اند. هدف از اين مقاله طراحى مكانيزم موقعيت دهى با مفاصل خمشى بر مبناى مدل شبه صلب و اصول طراحى مكانيزم هاى انعطاف

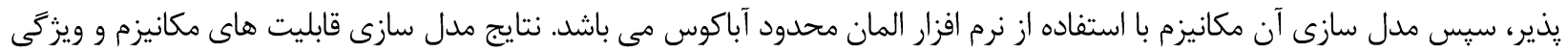
هاى فنى آن را مطابق محاسبات تاييد مى كند و امكان استفاده از اين مكانيزم را به عنوان موقعيت دهنده نانو ابزار نشان مى دهد. ويزگى هايى كه در طراحى مكانيزم مد نظر قرار ترفت عبارتند از سفتى مناسب مكانيزم در جهات مختلف، دسترسى مكانيزم و

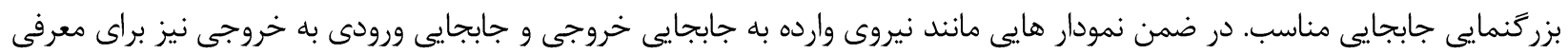
بهتر رفتار مكانيزم آورده داده شده است.

\section{r- مكانيزم انعطاف يذير يكيار گجه}

مكانيزم هاى انعطاف يذير يكيار خه مزاياى زيادى مانند كاهش تعداد قطعات، حذف زمان سوار كردن قطعات، ساده شدن روند توليد دارند كه منجر به كاهش هزينه مى شوند. از طرف ديخر افزايش دقت، افزايش اطمينان، كاهش سايش، كاهش وزن و نياز كمتر به نته دارى منجر به افزايش كارايى در استفاده از مكانيزم هاى انعطاف يذير يكيارجه مى شود. كاهش تعداد مفاصل بدليل كاهش يا حذف لقى دقت مكانيزم را نيز افزايش مى دهد [•او | ا]]. على رغم مزاياى بسيار تحليل و طراحى مكانيزم هاى انعطاف يذير بيجيده است و علم تحليل مكانيزم ها ، روش هاى ساخت و طراحى سازه هاى انعطاف يذير مورد نياز است . 


\section{r-}

يكى مفصل خمشى يك عضو باريك است كه حركت دورانى نسبى را بين دو عضو صلب از طريق خمش فراهمم م يكند. همانكونه كه

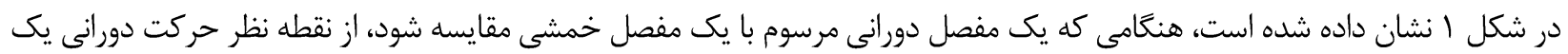

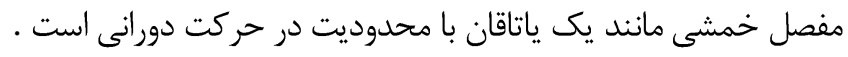

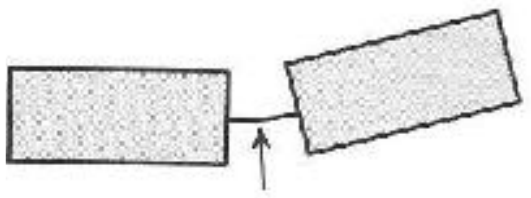

شكل ا: ب)مفصل خمشى

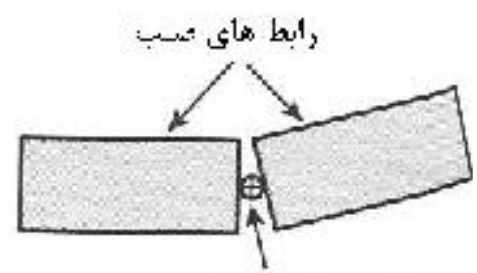

شكل ا: الف) مفصل دورانى

\section{r}

هدف از يك المان يا مكانيزم ايده آل محدود كننده آن است كه در جهت هاى محدود سفتى بى نهايت و جابجايى صفر ايجاد كند در حالى كه در بقيه جهات سفتى صفر و جابجايى بى نهايت است. جهت هايى كه محدود شده اند درجات مقيد، جهت هايى كه نه نامحدود

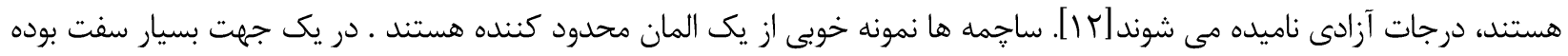

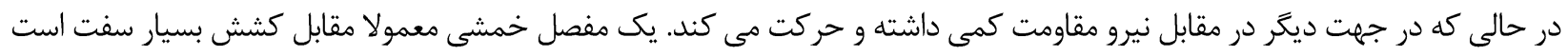

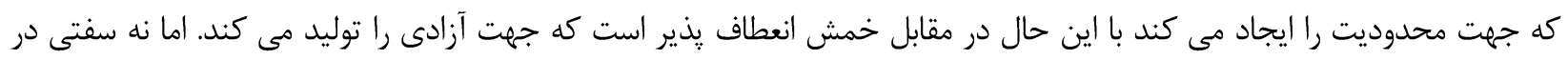

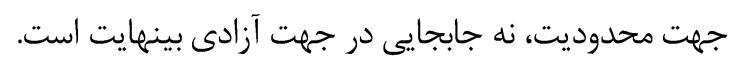

در مدل سازى و تحليل مكانيزم هاى خمشى مدل جسم شبه صلب روش تقريبا انحصارى است كه امروزه به كار مى رود. اين روش

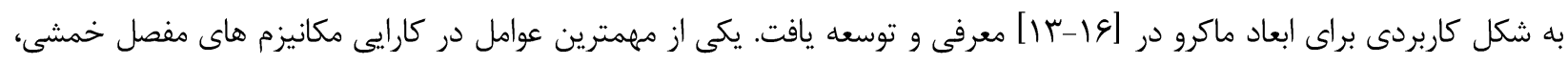

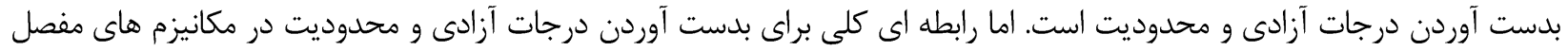

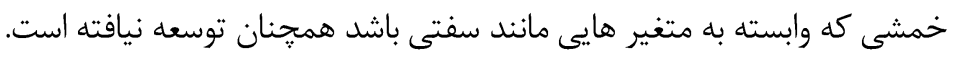

مقادير سفتى در جهات آزادى و محدوديت، كليد طراحى ديناميكى در سيستم هاى موقعيت دهى با كمك مكانيزم هاى مفصل خمشى هستند. به همين دليل در اين مكانيزم نيز اين مقادير محاسبه شده و از مدل شبيه سازى شده با نرم افزار المان محدود نيز استخراج 
دامنه كم جابجايى يكى ديكًر ويرّكىهاى مكانيزمهاى مفصل خمشى است. حداكثر جابجايى مجاز مكانيزم يكى از ازئ

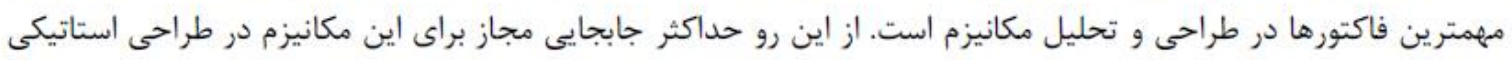
بدست آمده است.

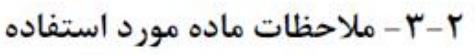

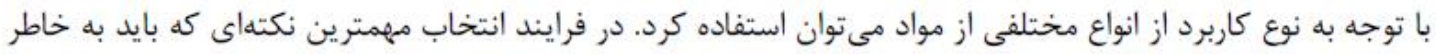

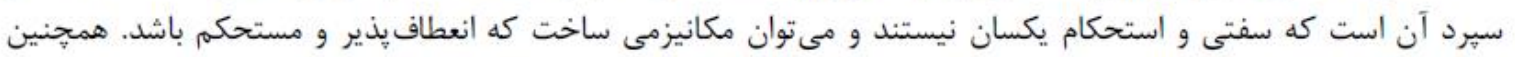

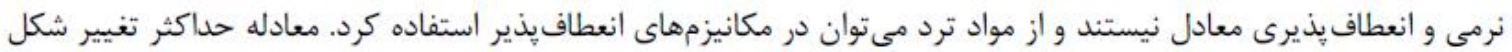
در يك تير ثابت در (1) آمده است.

$$
\delta_{\max }=\frac{2 S_{y} L^{2}}{3 E h}
$$

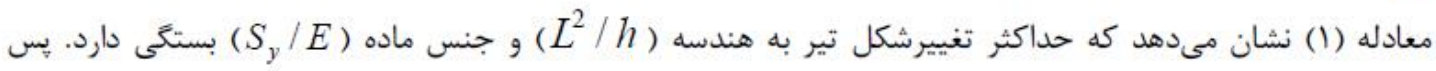

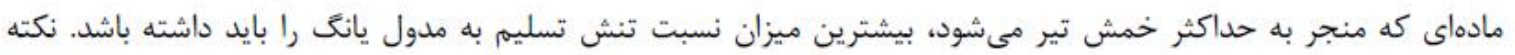

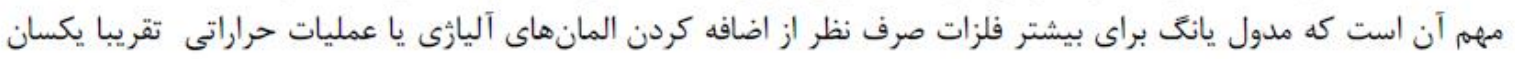

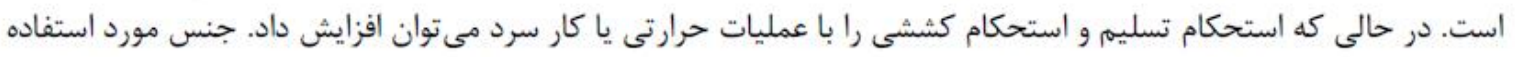

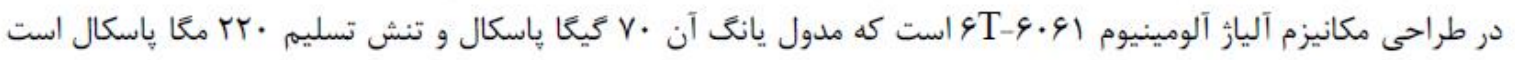
بنابراين نسبت S

r - ديفر انسيل سينماتيكى و ريبش بينى كارايى معادلات ديفرانسيل سينماتيكى مكانيزم موازى در [مو إنو شده در آنها استفاده شده است. رابطه بين جابجايى مفاصل فعال و جابجايى اصلى

$$
\Delta x_{T}=\underbrace{\left(J_{T_{a}}-J_{T_{P}} J_{C_{P}}^{\ddagger} J_{C_{a}}\right)}_{:=J_{I_{\text {canp }}}} \Delta q_{a}
$$

با اعمال اصول كار مجازى رابطه دوكانه زير بدست مىآيد:

$$
\underbrace{\left[\begin{array}{c}
\tau_{a} \\
\tau_{p}
\end{array}\right]}_{\tau}=\left[\begin{array}{cc}
J_{T_{a}}^{T} & J_{C_{a}}^{T} \\
J_{T_{p}}^{T} & J_{C_{p}}^{T}
\end{array}\right]\left[\begin{array}{l}
f_{T} \\
f_{c}
\end{array}\right]
$$

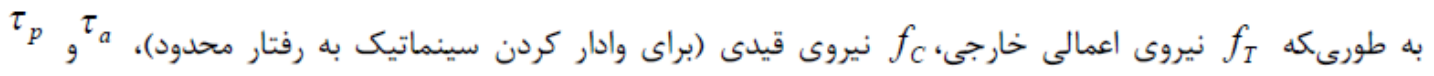

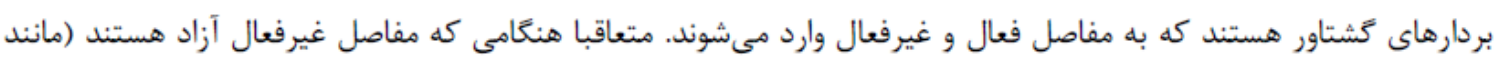

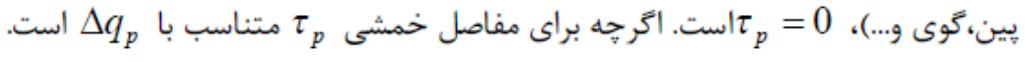


براى طراحى يك مكانيزم لازم است تا معيارهاى كارايى را كميت بخشيد. توجه به اين نكته ضرورى است كه برخلاف

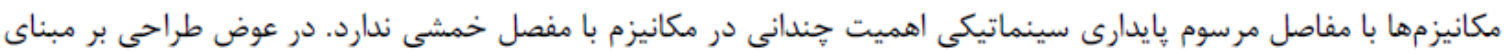

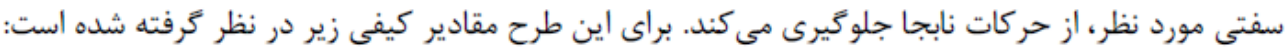

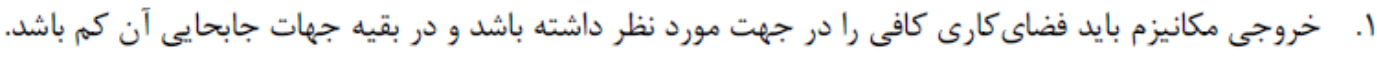

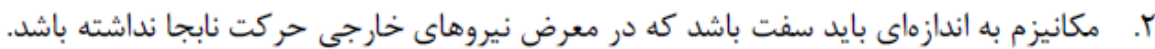

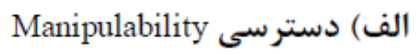

دسترسى مكانيزم توسط

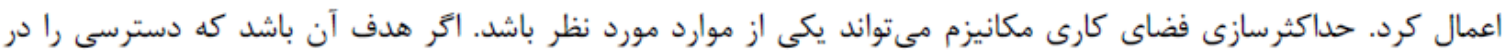

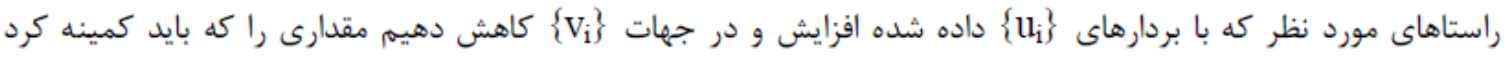
مى تواند مقدار تجمعى وزنى زير باشد.

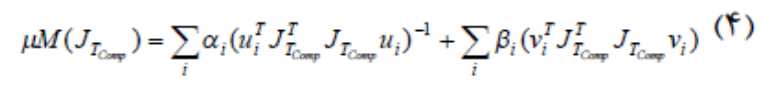
ب) حداكثر تنش مفصل

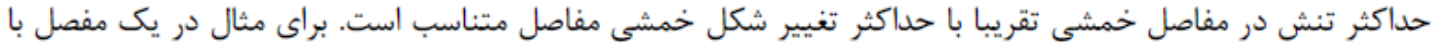

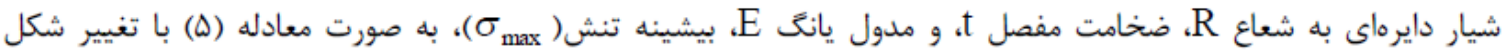
خمشى ( ) خ

$$
\theta_{\max }=\frac{3 \pi}{4 E} \sqrt{\frac{R}{t} \sigma_{\max }}
$$

اكر حداكثر تنش مفصل را داشته باشيم ( مثلا از تنش تسليم ماده مورد نظر)، اين قابل تبديل است به مقدار معادل حداكثر جابجايى مفصل(

$$
\left|\Delta q_{p}\right| \leq \Delta q_{p}^{\max }
$$

ج) جنى فضايى Task space stiffness

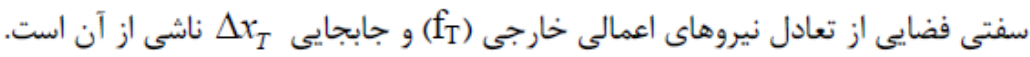

$$
f_{T}=K_{T} \Delta x_{T}
$$

با بازنويسى معادله تعادل نيروى (r) خواهيم داشت:

$$
\tau=J_{T}^{T} f_{T}+J_{C}^{T} f_{C}
$$

با استفاده از سيتماتيك ديفرانسيلى و اينكه گشتاور مفصل با جابهجايى مفصل به شكل يك فنر خطى متناسب است در

$$
\begin{aligned}
& \text { نهايت معادله براى سفتى فضايى بدين صورت بدست مى آيد } \\
& K_{q a}+J_{C_{a}}{ }^{T} J_{C_{a}}{ }^{-T} K_{q p} J_{C_{p}} J_{C_{a}}=J_{T_{\text {Conom }}}^{T} K_{T} J_{T_{\text {Canp }}}
\end{aligned}
$$

مشابه اين معادله نيز در [IV] آمده است. براى يك مفصل با شيار دايرهاى (شكل r) سفتى مفصل در [ץ] به صورت

$$
\text { خمش خالص با معادله · • مدل شده است: }
$$

$$
K \approx \frac{2 E p}{9 \pi} \sqrt{\frac{t^{5}}{R}}
$$


به طوريكه E مدول يانگ ماده به كار رفته مفصل، p ضخامت مفصل، t ضخامت باريكترين قسمت مفصل و R شعاع دايره است. مدل كامل ب بعدى سفتى مفصل در [ب] آمده است.

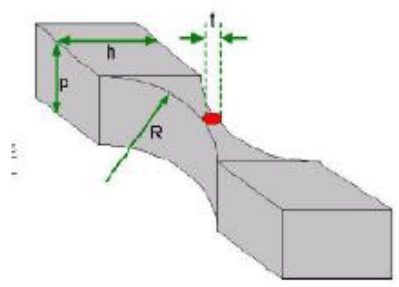

شكل ז: الف) مفصل با شيار دايرهاى

اكر هدف افزايش سفتى در جهات داده شده با بردارهاى $\left\{v_{i}\right\}$ و

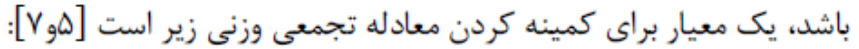

$$
\begin{aligned}
& \mu K\left(J_{T_{\text {Camp }}}\right)=\sum_{i} \alpha_{i}\left(u_{i}^{T} K_{T} u_{i}\right)^{-1}+\sum_{i} \beta_{i}\left(v_{i}^{T} K_{T} v_{i}\right) \text { (1) }
\end{aligned}
$$

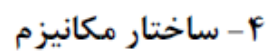

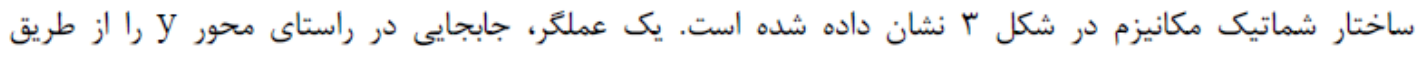

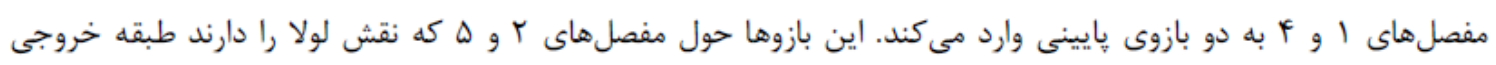

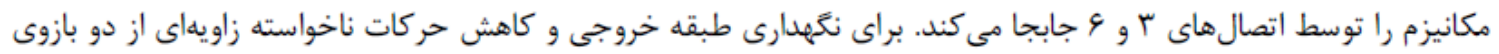
ديكر و مفصلهاى V- - - استفاده شده است.

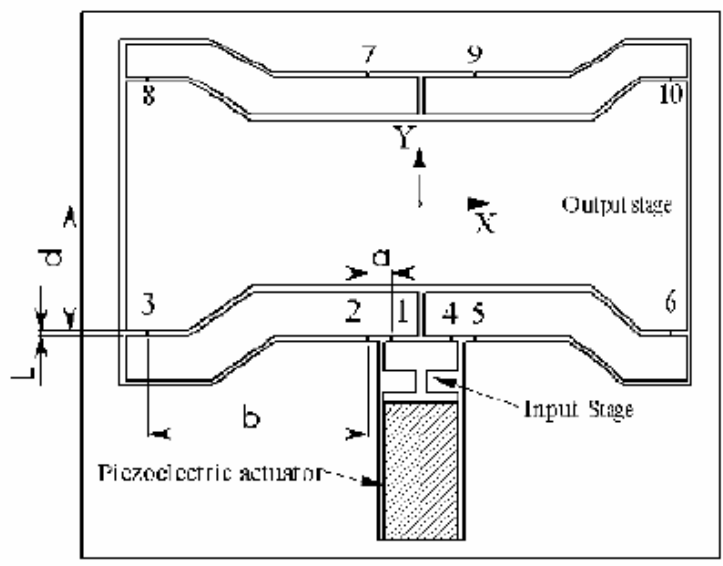

شكل r: نماى شماتيك مكانيزم يك درجه آزادى موقعيتدهى

هدف از اين طرح رسيدن به دسترسى مناسب( جابجايى خالص در راستاى YY) و سفتى مورد نظر (سفتى بالا در راستاها

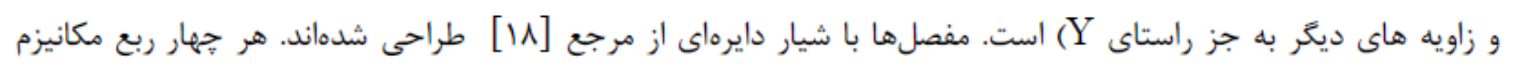
متقارن هستند و ابعاد زير به كار رفته است: a=1.5 mm, b=15 mm, L=0.425 mm, d=8.625 mm براى مفاصل با شيار دايرهاى ، سفتى غيرفعال مفصل با رابطه ( • () محاسبه شده است، بطوريكه:

$$
K_{P}=0.2140 \mathrm{~N}-\mathrm{m} / \mathrm{rad} \quad p=6.35 \mathrm{~mm} \text { ، } t=0.1 \mathrm{~mm} \text { ، } r=\frac{L}{2}=0.2125 \mathrm{~mm}
$$




$$
\text { سفتى عملكر نيز از مرجع [19 } 19 \text { بدست آمده است. }
$$

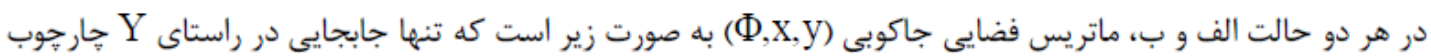

$$
\begin{aligned}
& J_{T_{\text {Camp }}}=\left[\begin{array}{c}
0 \\
0 \\
-9.9998
\end{array}\right] .
\end{aligned}
$$

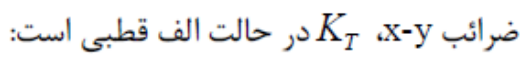

$$
\begin{aligned}
& K_{T_{(x, y)}}=\left[\begin{array}{cc}
1.4100 \times 10^{9} & -6.7705 \times 10^{-5} \\
-6.7705 \times 10^{-5} & 7.2841 \times 10^{5}
\end{array}\right] \mathrm{N} / \mathrm{m}
\end{aligned}
$$

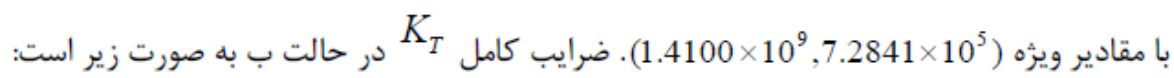

$$
\begin{aligned}
& K_{T}=\left[\begin{array}{lll}
6.9911 \times 10^{25} & 3.1518 \times 10^{16} & 2.4655 \times 10^{15} \\
3.1518 \times 10^{16} & 8.3672 \times 10^{8} & 1.1115 \times 10^{6} \\
2.4655 \times 10^{15} & 1.1115 \times 10^{6} & 6.4209 \times 10^{5}
\end{array}\right]
\end{aligned}
$$

مقادير ويثه ماتريس (6.

هستند. مقادير سفتى براى حالتهاى الف و ب به هم نزديك هستند، كه نشان دهنده سازكارى دو حالت است.

\section{ه - بهينه سازى طرح}

براى بهينهسازى طرح معيار حداكثرسازى دسترسى در راستاى ل و نسبت سفتى بين راستاى X و y در لنظر كرفته

$$
\begin{aligned}
& \mu_{1}=\frac{1}{\left\|J_{T_{\text {Comp }}}\right\|} \quad: \text { دستر (I T) } \\
& \mu_{2}=\frac{10}{K_{x} / K_{y}}
\end{aligned}
$$

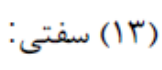

$$
\begin{aligned}
& \text { ثابت ضريبى كه اضافه شده براى نرمال كردن دو معيار است. }
\end{aligned}
$$

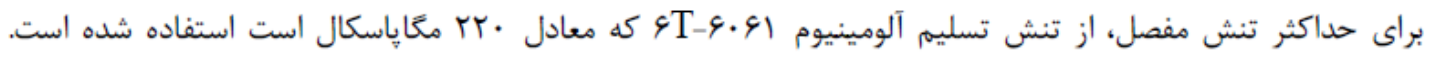
حداكثر تنش هنكامى اعمال مىشود كه مفصل فعال در بيشترين كشش

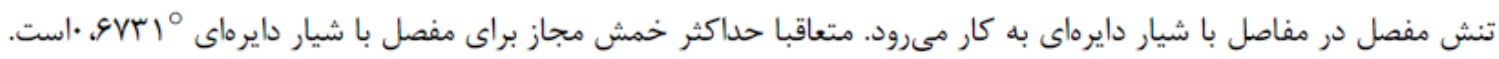
(پ,b,L)

$$
\begin{gathered}
0.5 \mathrm{~mm} \leq a \leq 4.5 \mathrm{~mm} \\
5 \mathrm{~mm} \leq b \leq 45 \mathrm{~mm} \\
0.08 \mathrm{~mm} \leq L \leq 0.75 \mathrm{~mm}
\end{gathered}
$$

با روش مرزهاى ڤارتو براى حالت الف و ب ضرايب معيارهاى بهينه سازى با وزنهاى برابر (

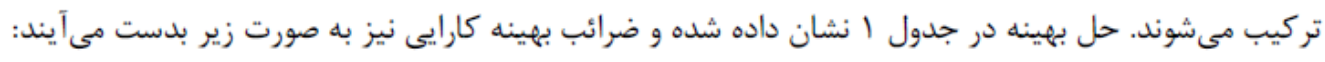

$$
\text { حالت الف) حسترسى = }
$$

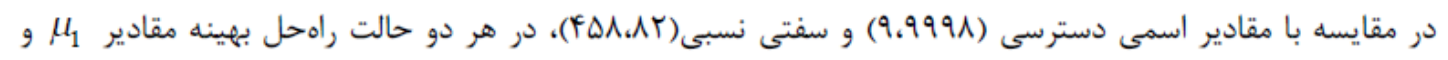

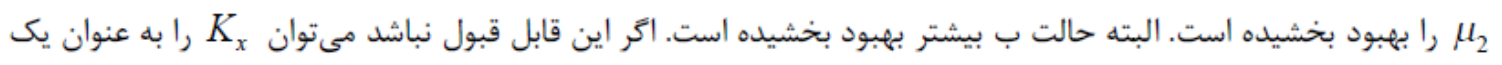

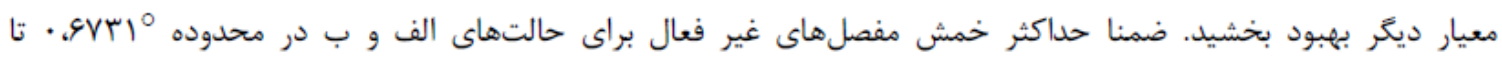

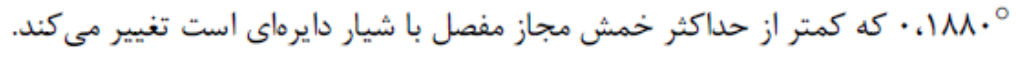




\begin{tabular}{|c|c|c|c|}
\hline \multicolumn{2}{|c|}{ مفدار بهيينه } & \multirow[b]{2}{*}{ مقدار اوليه } & \multirow[b]{2}{*}{ بارامترهاى طراحى } \\
\hline حالت ب & حالت الف & & \\
\hline $1.3 \mathrm{~mm}$ & $1.2 \mathrm{~mm}$ & $1.5 \mathrm{~mm}$ & a \\
\hline $18.5 \mathrm{~mm}$ & $18.6 \mathrm{~mm}$ & $15 \mathrm{~mm}$ & $\mathrm{~b}$ \\
\hline $0.379 \mathrm{~mm}$ & $0.506 \mathrm{~mm}$ & $0.435 \mathrm{~mm}$ & L \\
\hline
\end{tabular}

$$
\text { 9- شبيهسازى مكانيزم و مقايسه نتايج }
$$

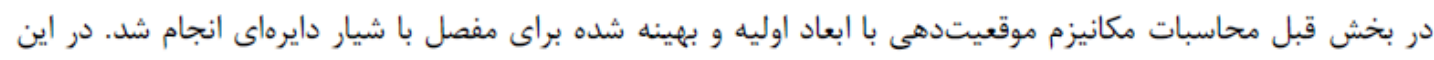

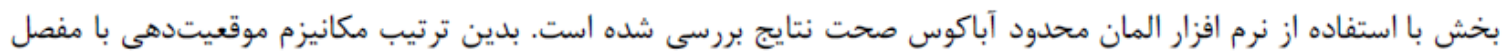

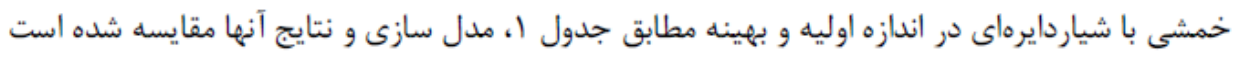

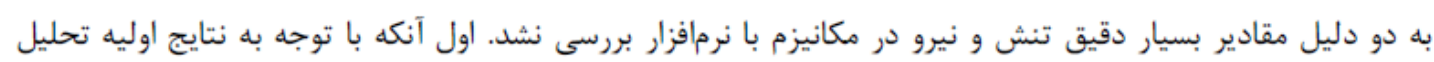

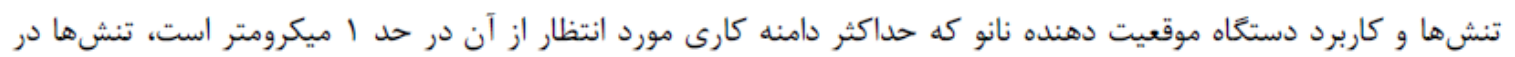

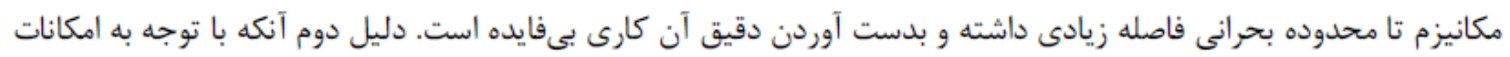

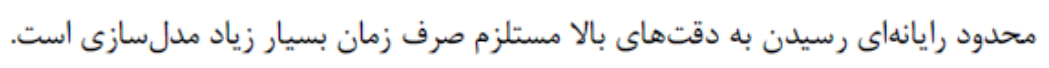

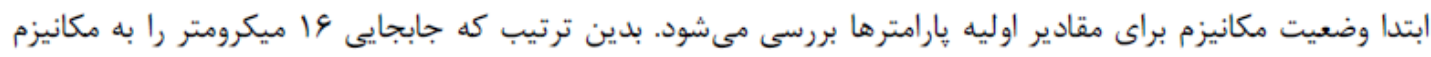

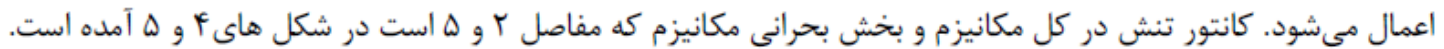
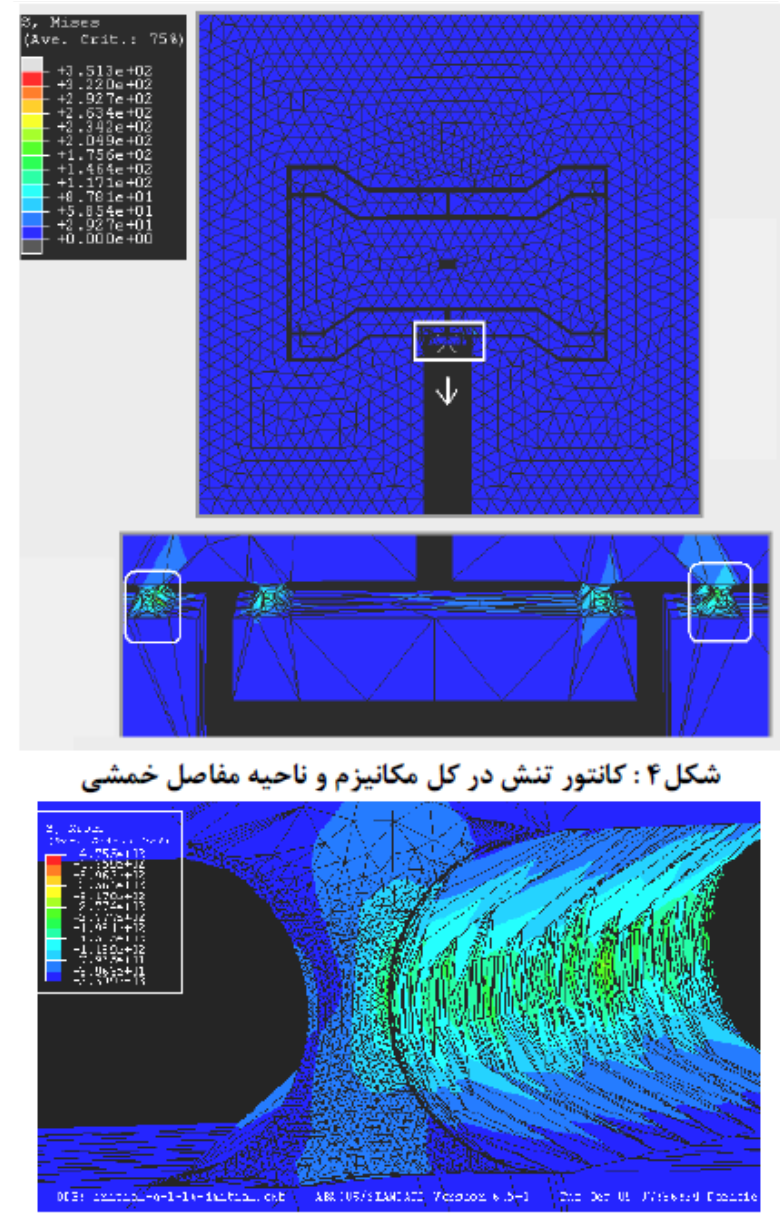

شكل ه : كانتور تنش در مفصل r با بحر انى ترين وضعيت 


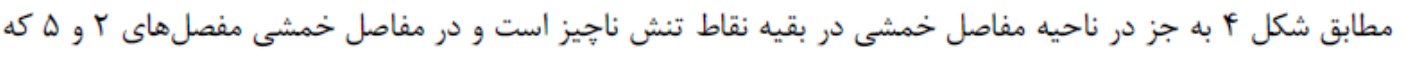

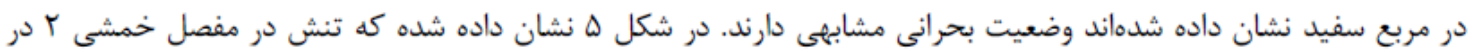

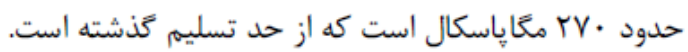

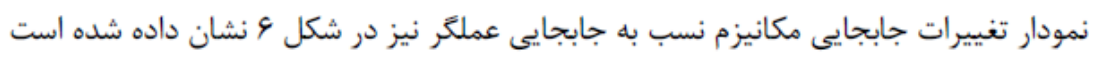

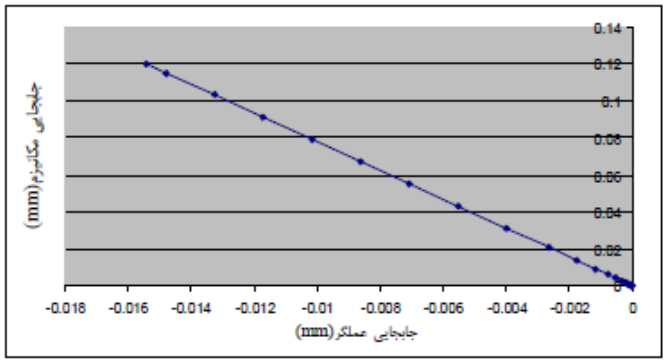

شكل 9 :نمودار جابجايى بستر مكانيزم برحسب جابجايى عملكر

مطابق شكل \& جابجايى عملكر در جهت بالا (منفى) و جابجايى بستر مكانيزم برعكس است. مفاصل خمشى قبلا نيز

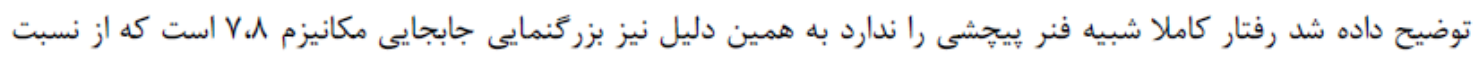

$$
\text { اهرمى } 10
$$

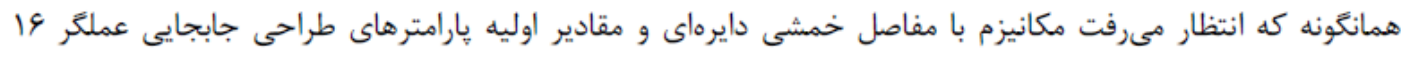

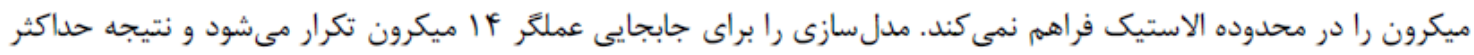

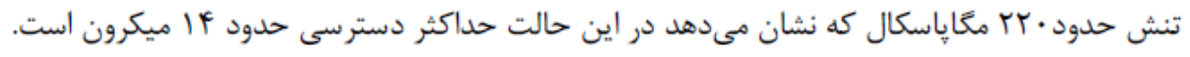

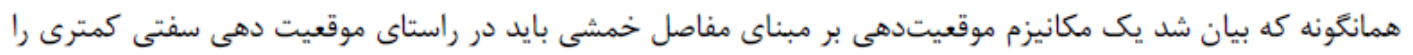

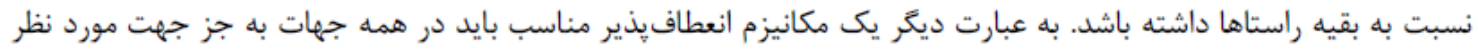

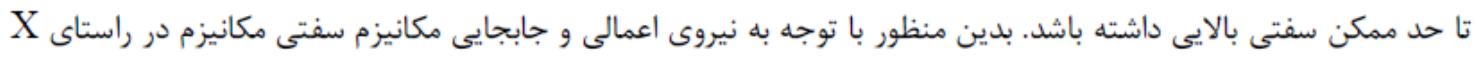

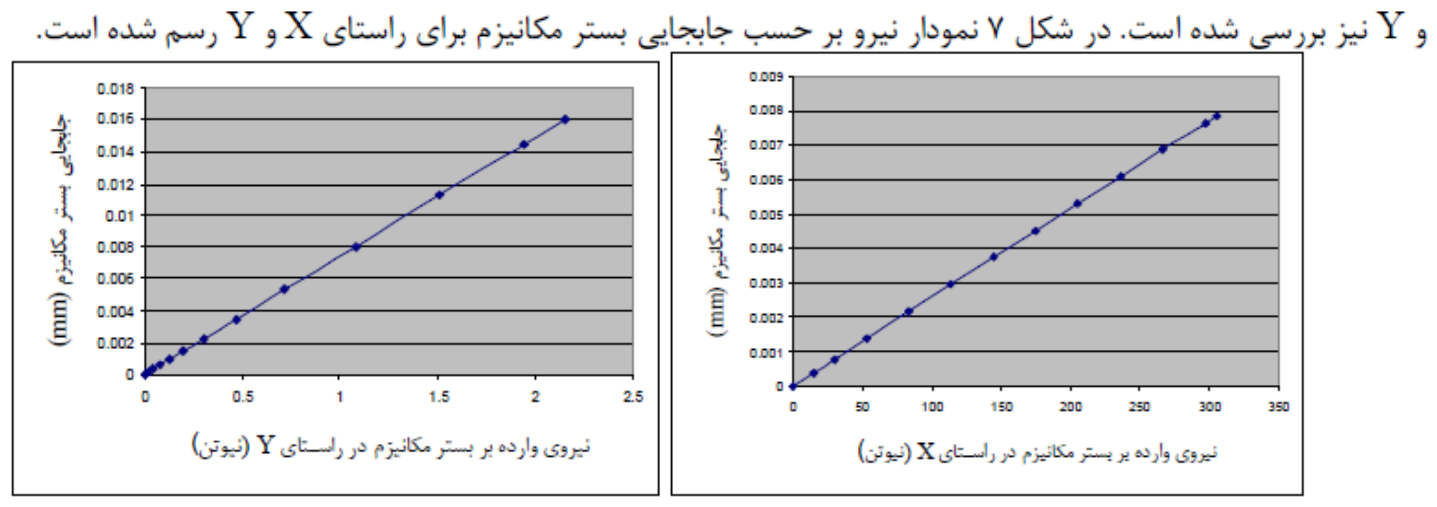

شكل V: جابجايى بستر مكانيزم بر حسب نيروى در راستاى X و

قابل توجه است كه در اين نمودارها نيرو به بستر خروجى مكانيزم وارد شده و از آنجايى كه مكانيزم در راستاى

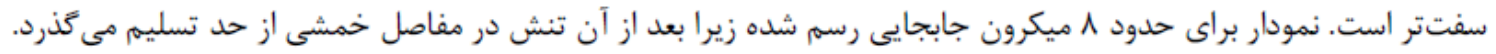

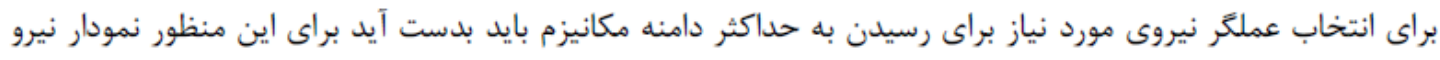

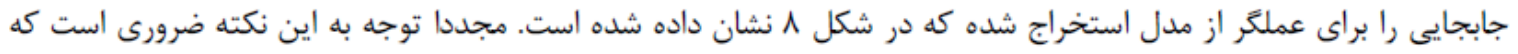

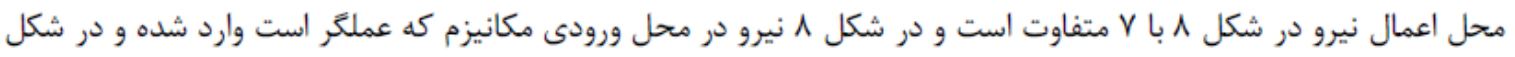
V له بستر خروجى مكانيزم نيرو وارد شده است. 


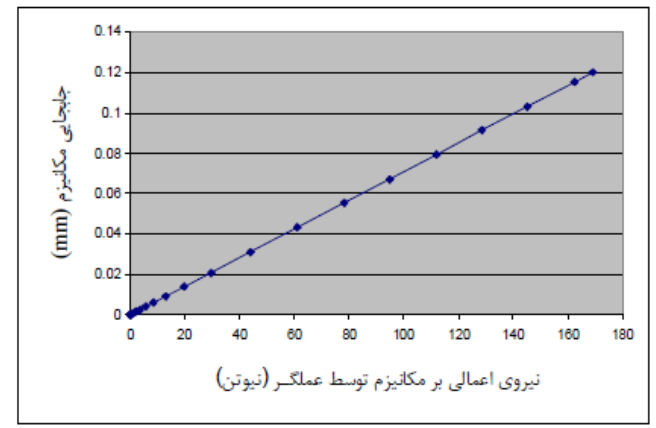

شكل ^: نمودار جابجايى بستر مكانيزم برحسب نيروى عملكر

نتايج مهمم شكل هاى V و 1 در جدول Y نشان داده شده است. جدول r: مشخصات مكانيزم با مفصل خمشى دايرهاى و و مقادير اونس اوليه

\begin{tabular}{|c|c|c|}
\hline راستاى Xبت سفتى & $\begin{array}{c}\text { سفتى در راستاى } \\
\text { (N/mm) }\end{array}$ & $\begin{array}{c}\text { Xفتى در راستاى } \\
\text { (N/mm) }\end{array}$ \\
\hline$r \wedge \Delta$ & Irf & rAfQ. \\
\hline نسبت بزرگنمايى & براى حداكثر مامنه (N) لازم عملكر & جابجايى عملكَ داكثر مجاز \\
\hline V.A & $1 \Delta F$ & if \\
\hline
\end{tabular}

حالت الف با مقادير بهينه كليه مراحل قسمت قبل براى اين حالت نيز تكرار شد و نتايج در جدول ب آمده است. جدول r: مشخصات مكانيزم با مفصل خمشى دائ دايرهاى و و مقادير بهينه

\begin{tabular}{|c|c|c|}
\hline 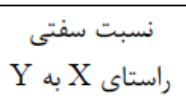 & $\begin{array}{c}\text { سفتى در راستاى } \\
\text { (N/mm) }\end{array}$ & $\begin{array}{c}\text { سفتى در راستاى } \\
\text { (N/mm) }\end{array}$ \\
\hline fFD & 11 & $r \varphi \cdot \Delta$. \\
\hline نسبت بزر گنمايى & 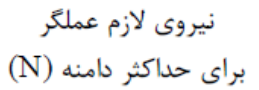 & جابجايى عملكر دامنه مجاز \\
\hline $11 . r$ & זי. & 10 \\
\hline
\end{tabular}

همانكونه كه انتظار مى رفت با بهينه كردن يارامترهاى طراحى نسبت سفتى به ميزان قابل توجهى افرايش يافته ضمن اينكه حداكثر جابجايى مكانيزم نيز زياد شده است.

\section{- بحث و نتيجه كيرى}

مدل سازى نتايج بدست آمده در بخش محاسبات را تاييد مى كند. بدينترتيب محاسبات و مدلسازى نشان داد با بهينه كردن ابعاد مكانيزم در مفصل دايرهاى نسبت سفتى مكانيزم در راستاى X به Y افزايش قابل ملاحظهاى داشته كه اين تغيير در كارايى مكانيزم و كاهش خطاهاى ناخواسته تاثير زيادى دارد. بعلاوه آنكه با بهينه كردن ابعاد در هر دو حالت دالت حداكثر دامنه مجاز جابجايى مكانيزم افزايش يافته است. مكانيزم با مفاصل دايرهاى نسبت به ديخر مفاصل مانند ستونى دامنه جابجايى

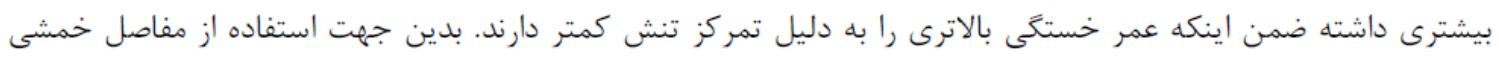

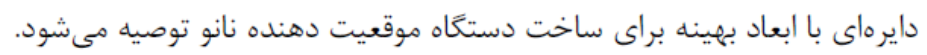




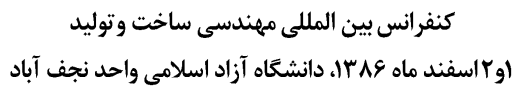

\section{مراجع}

1- L.L Howell, Compliant Mechanisms, 2001 John Wiley and Sons, Inc .

2- S. Kota, Compliant systems using monolithic mechanisms, 2000 Smart Material Bulletin. pages 7-9.

3- Smith S.T., Flexures: Elements of Elastic Mechanisms , 2000, Gordon and Breach Science Publishers.

4- Lobontiu, Nicolae, Compliant Mechanisms Design of Flexure Hinges, 2003 CRC Press.

5- Zarreh, A., 2008. Design and manufacturing evaluation of microlathe with nano positioning stage (Thesis, The University of Tehran).

6- A. Zarreh, M.S. Sepasi, M. Sadeghi, Design and Developing a Linear Tables by Applying Piezoelectric Inchworm Moves, 2008, 1st International Manufacturing Engineering Conference, Najaf Abad, Iran.

7- Hun Kang, B.,Wen, J., Dagalakis, N., Gorman, J.. Design optimization for a parallel mems mechanism with flexure joints, Proc. Of 2004 ASME Design Engineering Technical Conferences.

8-M.L. Culpepper and G. Anderson, Design of a low-cost nanomanipulator which utilizes a monolithic spatial compliant mechanism, 2003, J. of Precision Engineering.

9- H.H. Pham and J.M. Chen, Optimal synthesis for workspace and manipulability of parallel flexure mechanism, .2003, 11th World Congress in Mechanism and Machine Science, Tianjin. China.

10- Mostsinger, R. N., Flexural Devices in Measurement Systems, 1964 Chapter 11 in Measurement Engineering, by P. K. Stein, Stein Engineering Services, Phoenix,AZ.

11- Tuttle, S. B., Semifixed Flexural Mechanisms, Chapter 8 in Mechanisms for Engineering Design, (1967).Wiley, New York.

12- Shorya Awtar, Synthesis and Analysis of Parallel Kinematic XY Flexure Mechanisms, 2003 Ph.D. Thesis, Massachusetts Institute of Technology,

13- Midha, A., Her, I., and salamon, B.A., A methodology for compliant mechanisms design., 18th ASME Design Automation Conference, 1992. p.29.

14- Howell, L.L. anf Midha, A., A method for design of compliant mechanisms with smalllength flexural pivots, ASME Journal of Mechanical Design, 1994.

15- Howell, L.L. and Midha, A., Parametric deflection approximations for end-loaded, largedeflection beams in compliant mechanisms, 1995 ASME Journal of Mechanical Design, 117(1), 156.

16- Howell, L.L and Midha, A., Determination of the degrees of freedom of compliant mechanisms using the pseudo-rigid-body model concept,1995, Proc. Of the 9th World Congress on the Theory of Machines and Mechanisms, Milano, Italy, 2, p. 1537. 


$$
\begin{aligned}
& \text { كنفرانس بين المللى مهندسى ساخت وتوليد }
\end{aligned}
$$

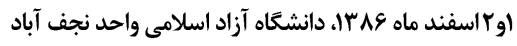

17- G.Alici and B. Shirinzadeh. Kinematics and stiffness analyses of a flexure-jointed planar micromanipulation system for a decoupled compliant motion. In Proceedings of the 2003 IEEE/RSJ Intl. Conference on intelligent Robots and Systems, Las Vegas. NV, October.

18- E. Amatucci, N.G. Dagalakis. J.A. Kramar, and F.E. Scire. Performance evaluation of a parallel cantilever biaxial micropositioning stage, 2000, In Proc. of the American Society of Precision Engineering. 15th Annual Meeting. Scottsdale. Arizona.

19- J.J. Garman, N.G. Dagalakiis, and B.G. Boone., Multi-Ioop control of a nanopositioning mechanism for ultraprecision beam steering. In Free- Space laser Communication and Active Laser Illumination III, 2003, SPIE Vol. 5160, pages 170-181, San Diego, CA. 